\title{
On congenital heart disease in developing countries
}

\author{
Tjark Ebels \\ University of Groningen, Groningen, The Netherlands
}

$\mathrm{T}$ HE PAPERS IN THIS ISSUE BY AL JUBAIR AND his colleagues ${ }^{1}$ on a large series of BlalockTaussig shunts, and by Asou and Rachmat ${ }^{2}$ on the state of congenital heart disease in Indonesia, are illustrative examples of the vast differences presently to be found in health care across the world. These differences are also reflected, and probably even enlarged, regarding the management of children with congenital heart disease. Comments, though, from an exponent of the western world, and specifically from the former colonial power in Indonesia, must be received at best with scepticism! They could also be regarded as presumptuous, arrogant, and as a new age form of colonial meddling in internal affairs. This stance, however, would make it virtually impossible to give any comment at all. I shall try, therefore, to put the situation into perspective and give some cautious comments. Hopefully, we can then enter into a fruitful dialogue as to the wisdom of future developments in paediatric cardiology.

I should start, however, by commenting that the authors deserve considerable praise for their efforts. To the best of my knowledge, no other paper has been published dealing with such a large number of Blalock-Taussig shunts. The results from Saudi Arabia ${ }^{1}$ are outstanding, and risk factors for failure have been elegantly analysed. The conclusion to be drawn is that this procedure is still the gold standard for shunt operations, and can be performed with very low mortality, providing a major improvement in health status of the children undergoing surgery. The Saudis found no difference in

Correspondence to: Tjark Ebels, MD, Chief, Thoraxcentrum Academisch Ziekenhuis Groningen, P O Box 30.001, 9700 RB Groningen, The Netherlands. Tel: 3150361 3238; Fax: 3150361 1347; e-mail: T.Ebels@thorax.azg.nl

Accepted for publication 1 June 1998 patency between classical and modified shunts (with a vascular prosthesis), but perioperative heparin, and postoperative aspirin, positively influenced patency. Their early rate of failure was $1.6 \%$, which should be an achievable goal for all paediatric cardiac surgeons. Their results are remarkable and very relevant, because this is a sound operation, establishing superb palliation until circumstances, in whatever way, are favourable for repair.

Some of the foremost surgeons in the western world, however, are now able, with their technical skills and fine-tuned infrastructure, to skip the shunt and achieve definitive repair in neonates in a number of anomalies, most frequently tetralogy of Fallot. ${ }^{3}$ If this operation can be done with results equal to those obtained with the staged strategy, then the single operation is obviously preferable. I have doubts, however, if complete repair is achievable by all surgeons, and in all health care settings. The reverse of the argument, then, is that a staged strategy is obviously preferable if a single operation produces inferior results, for whatever reason. The skilful execution of a shunt operation, as performed by Al Jubair and colleagues, ${ }^{1}$ is then the essential first step in the operative cascade. When Alfred Blalock performed his first shunt operations in collaboration with Helen Taussig, a second, final, repair was not available, so the shunt was the final palliation. Many patients in that day and age never had a final repair and lived their lives with a handicap, being somewhat cyanotic and limited in their exercise tolerance. ${ }^{4}$ Do situations exist in the world today where this would still be a beneficial strategy? I believe they do, and I shall come back to this consideration.

The situation of paediatric cardiac surgery in Indonesia presents a stark contrast to that found in 'the western world'. Asou and Rachmat ${ }^{2}$ report that only $1 \%$ of all 47,000 children born with a congenital cardiac defect in Indonesia is being treated properly. The reason is one of resources, not 


\begin{tabular}{llll}
\hline & Indonesia & Saudi Arabia & The Netherlands \\
\hline Population & $203,000,000$ & $19,500,000$ & $15,500,000$ \\
Life expectancy & 62.3 & 68.5 & 77.5 \\
Crude birth rate & 24.8 & 35.1 & 13.0 \\
No. of children born annually* & $5,034,400$ & 684,450 & 201,500 \\
Infant mortality rate & 53 & 18 & 6.3 \\
Physicians per 10,000 population & 1.4 & 14.2 & 24.2 \\
Nurses per 10,000 population & 3.5 & 32.3 & 78.1 \\
Total national health expenditure as \% of GNP & 3.7 & 8.0 & 5.5 \\
Total government health expenditure as \% of GNP & 0.7 & 3.1 & 0.008 \\
Probability of dying before 5th birthday & 0.059 & 0.028 & 7 \\
Maternal mortality rate (per 100,000 live births) & 425 & 18 & $?$ \\
Mortality from diarrhoeal diseases in children & & 4,906 & 100 \\
$\quad<5$ years (no. of deaths) & 130,988 & 76.0 & 8 \\
\% population with safe drinking water & 64.8 & 952 & 1063 \\
Prevalence of leprosy & 43,813 & 800 & \\
Incidence of tuberculosis (annual no. of cases) & 49,647 & & \\
\hline
\end{tabular}

* Calculated by multiplying the crude birth rate with the population, divided by 1000

of choice. Funding is lacking for these expensive operations, as it is lacking in other sectors of health care. Surgeons, nurses and pump technicians are lacking, and so are the facilities. One institution has been established with generous help from Japanese and Australian colleagues. The strategy to achieve a level playing field with 'the western world' is primarily the responsibility of the Indonesians themselves, but given the fact that it is physically impossible to do so in a brief period of time, what would be their wisest option?

In trying to set this problem in its context, it is essential to realise the incredible strides forward that Indonesia has made in the last decades. Indonesia is among the best performing East Asian economies. Its Gross Domestic Product grew at a rate of $7.1 \%$ between 1985 and 1995. The benefits of this growth have extended across all of Indonesia's 27 culturally diverse provinces. The quality of life for the average Indonesian has improved significantly. Infant mortality declined from 145 per 1,000 live births in 1970 to 53 per 1,000 in 1995 while, in the same period, life expectancy rose from 46 to 63 years. ${ }^{5}$ It is now possible with the help of the Internet, ${ }^{6-8}$ to compare data from Indonesia, Saudi Arabia and the Netherlands (Table).

The inferences that can be drawn from these data are numerous. First, Indonesia has a serious shortage of doctors and nurses, so a major effort is needed to educate new practitioners. This effort, when it gets started, has a latent period of several years, so for the short term no effect on healthcare can be expected. Second, the government should put more funding into healthcare, but then it will have to decide on its priorities. In a country where the birth rate is overwhelming, and many children die from easily treated and prevented diseases such as diarrhoea, leprosy and tuberculosis, these should be the initial priority for public health care. Nonetheless, it would not be wise to deflect attention completely from paediatric cardiac surgery. In a country so short of funding and trained professionals, the greatest impact on healthcare is to be expected from a starting point of cheap and effective operations, combined with the process of education as an ongoing effort.

Coming back to the Blalock-Taussig shunt, the largest number of children can be helped if such a shunt is constructed in all children with tetralogy of Fallot. When we estimate this lesion to be present in at least $5 \%$ of all 47,000 children born each year with a congenital cardiac defect in Indonesia, this would amount to 2,350 children each year. Final repair can then be deferred until funds and professionals are available. Children with a large ventricular septal defect can likewise undergo banding of the pulmonary trunk, again deferring complete repair. Unless, of course, Indonesia could set up in the meantime an industry of its own, producing the necessary equipment and disposables, such as oxygenators, for its own domestic market, which is potentially huge. If open-heart surgery could thus be made considerably cheaper, both health care and the economy would benefit, and thousands of doctors and nurses would have a job. In the end, the children born with a congenital cardiac malformation would have the chance for proper treatment, at present unavailable for $99 \%$.

\section{References}

1. Al Jubair KA, Al Fagih MR, Al Jarallah AS, Al Yousef S, Ali Khan MA, Ashmeg A, Al Faraidi Y, Sawyer W. Results of 546 
Blalock-Taussig shunts performed in 478 patients. Cardiol Young 1998; 8 (4): 486-490

2. Asou T, Rachmat J. Pediatric cardiac surgery in Indonesia. Cardiol Young 1998; 8 (4): 437-439

3. Hennein HA, Mosca RS, Urcelay G, Crowley DC, Bove EL. Intermediate results after complete repair of Fallot in neonates. J Thorac Cardiovasc Surg 1995; 109: 332-342.

4. Rostad H, Efskind L. Long-term shunt palliation for Fallot's tetralogy. Scand J Thorac Cardiovasc Surg 1976; 10: 126130 .
5. Indonesia, the World Bank Group. http://www.worldbank.org/html/extdr/offrep/eap/in.htm

6. Indonesia, World Health Organisation. http://www.who.org/hst/hsp/a/countrys/ino $1 . h t m$

7. Saudi Arabia, World Health Organisation. http://www.who.org/hst/hsp/a/countrys/saus.htm

8. Netherlands, World Health Organisation. http://www/who.org/hst/hsp/a/countrys/net6.htm

9. Indicators on population, United Nations. http://un.org/Depts/unsd/social/poptn.htm 